\title{
COVID-19 and schooling in South Africa: Who should go back to school first?
}

\author{
Nic Spaull ${ }^{1}$
}

Published online: 28 May 2020

(C) UNESCO IBE 2020

\begin{abstract}
The COVID-19 pandemic is the largest social and economic shock of our lifetimes. As governments grapple with their responses to the virus, more than half the world's countries have closed their schools and severely limited almost all forms of public life. This will have a profound impact on children, both now and in the decade to come. As many countries start to send children back to school, a question arises: who should go back to school first? This Viewpoint addresses that question in the context of a middle-income country, South Africa. Based on a review of much of the evidence available at the time of publication, it concludes that the youngest children are least susceptible to harm from COVID-19, are less likely to spread the virus than adults, and also have the most to lose by being out of school. Hence, they should be the ones to return to school first.
\end{abstract}

Keywords COVID-19 $\cdot$ Schooling $\cdot$ South Africa $\cdot$ Age $\cdot$ Children $\cdot$ Education policy

The question of when and how children should return to school depends on three main points: (1) risks to children of illness and death, (2) transmission of the virus from children to adults and the need to "flatten the curve", and (3) the social and economic costs of keeping children at home. The Viewpoint below presents evidence on these three issues and argues that when children go back to school, the youngest should go back first.

Overview of research on children and COVID-19. There is a clear and emerging consensus in the international research literature across all countries: children aged $0-10$ years old are considerably less likely than adults to get infected, either from each other or from adults. They are also less likely to transmit the virus, even when they are infected, and it is extremely rare for them to get severely ill or die from COVID-19. (Most current research comes from high-income countries-with the exception of China and Iran-, mainly

Nic Spaull

spaull@sun.ac.za

1 Economics Department, Stellenbosch University, Stellenbosch Central, Stellenbosch 7600, South Africa 
because high-income countries experienced the outbreak first and their research response has been the largest. They have also conducted the most screening and testing and therefore have the most reliable indicators of transmission.)

Why the youngest should go back first. In addition to young children's lower chance of infection, they also present the highest childcare burden to their households. This prevents many parents and caregivers from going back to work and earning an income to support their families. Any attempt to mitigate the economic disaster from the lockdown and COVID-19 must take account of parents' additional childcare responsibilities while schools are closed. Similarly, young children are also the least able to follow self-directed learning at home. This is partly because they have not yet learned to read by themselves, but also because young children simply require higher levels of human interaction and "activity" to learn. For most children in South Africa, all curricular learning has stopped while schools are closed, leading to further inequalities in learning outcomes.

Finally, children's well-being increases when they can go to school. Children receive free school meals to supplement their diet, they can interact with their same-age peers, and it gives their caregivers a break from otherwise constant childcare. This improves parents' mental health and allows them to work, plan, and relax, making them better caregivers when children come back from school. Being "locked-up" at home, especially when there are few health benefits to themselves or society, is bad for children, bad for parents, and bad for the economy.

Using research to inform policy responses. Judgments about the national threat posed by COVID-19 and mitigation strategies should be informed primarily by advice from virologists and epidemiologists (the author is neither). However, the Department of Basic Education in South Africa, in consultation with these experts, has already decided that schools will resume starting June 1, 2020, starting with Grade 7 and Grade 12. However, a better phase-in approach would be to open ECD sites at the same time that Grade 12 goes back, then allow Grades R, 1, 2 and 3 (rather than Grade 7) to return incrementally, with special precautions for teachers. This should be combined with close monitoring of infection rates among a random sample of teachers and families of Grade R-3 children. There is a clear rationale for this alternative, informed by the best available research. Such an approach minimizes the risk to learners and teachers and allows many parents to go back to work. In short, children should go back to school and the youngest should go back first.

\section{The international research on COVID-19 and children}

The evidence emerging from countries around the world is clear and consistent: children are less likely to catch COVID-19 and they almost never die from it. The graph below shows the fatality rates from COVID-19 by age group for China, Italy, Spain, and South Korea. The data reflects all deaths up to 24 March 2020 (Our World in Data 2020). A clear age bias is evident, with less than $0.3 \%$ of fatalities among those less than 40 years of age and $0 \%$ in the $0-9$-year-old category. 


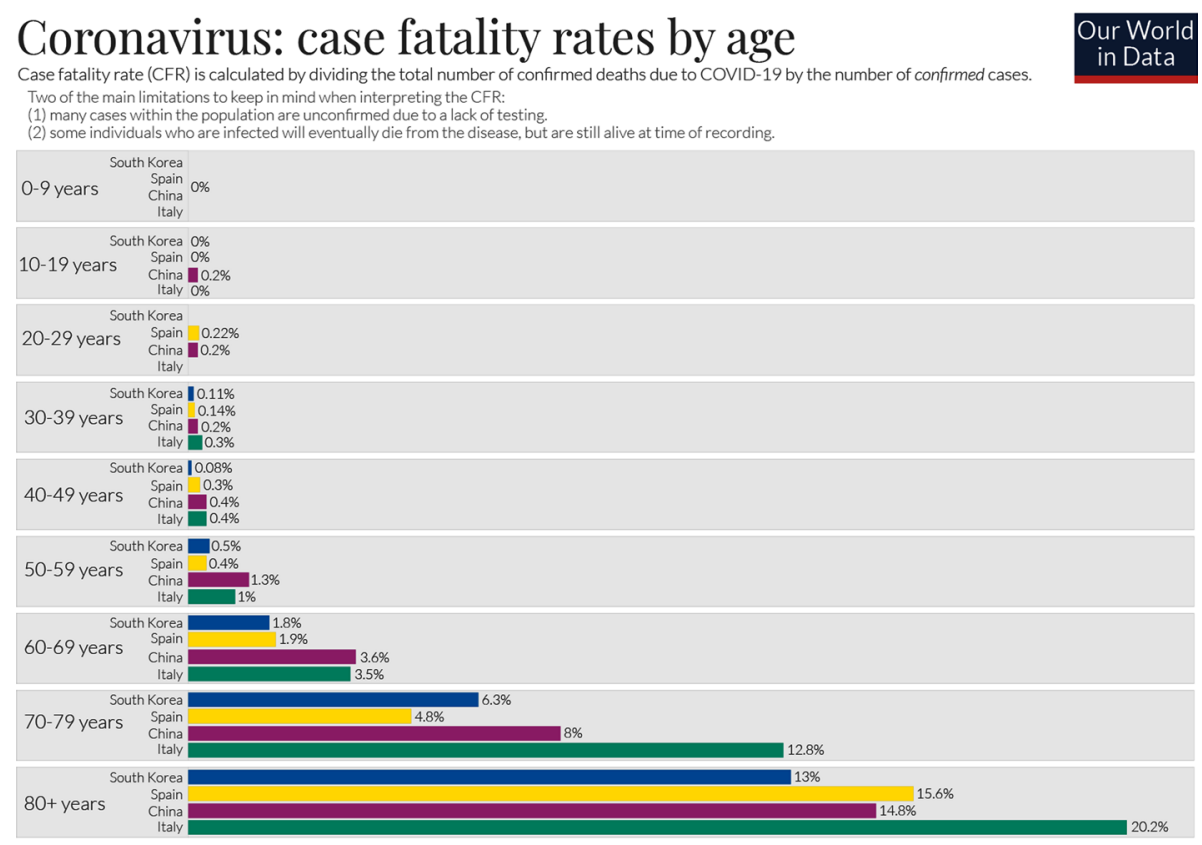

Note: Case fatelity rates are based on confirmed cases and deaths from COVID-19 as of: 17th February (China): 24th March (Spain): 24th Merch (South Korea): 17th March (Italy).

Data sources: Chinese Center for Disease Control and Prevention (CDC); Spanish Ministry of Health; Korea Centers for Disease Control and Prevention (KCDC).

OurWorldinData.org - Research and data to make progress against the world's largest problems.

Included below is a short summary of authoritative research studies reviewing the COVID19 outbreak in different countries, with a special focus on children. To date the best available evidence on whether children can catch and transmit COVID-19 comes from Iceland, since they have tested the largest percentage of their population.

Iceland. In their 14 April 2020 article in the New England Journal of Medicine, Gudbjartsson et al. (2020) reported that "In the population screening, no child under 10 years of age had a positive result, as compared with $0.8 \%$ of those 10 years of age or older. Even amongst a pre-selected high-risk group that had likely exposure to the virus, children under the age of ten were half as likely to test positive compared to those older than 10". Furthermore, the CEO of deCODE genetics, a genetic sequencing company working with the Icelandic Directorate of Health to trace all COVID-19 infections, explained in an interview that "[c]hildren under 10 are less likely to get infected than adults and if they get infected, they are less likely to get seriously ill. What is interesting is that even if children do get infected, they are less likely to transmit the disease to others than adults. We have not found a single instance of a child infecting parents" (Science Museum Group 2020).

South Korea. The Korean experience is notable because it was one of the first countries to undertake widespread community testing. In a study looking at the first 7755 confirmed cases of COVID-19 in Korea, only $1 \%$ of cases were among the $0-9$ age group (Jeong et al. 2020). There were no fatalities for any patient under 30 years of age.

Switzerland. In May 2020, the Swiss health ministry's infectious diseases chief, Daniel Koch, reported that after wide consultation with clinicians and researchers, "young children are not infected and do not transmit the virus. They just don't have the receptors to catch the disease". Koch went on to say that children under the age of 10 in Switzerland can now hug 
their grandparents (BBC News 2020). This is now the official policy in Switzerland and has subsequently been supported by infectious-diseases paediatricians and the Swiss Pediatric Society (RTS 2020).

United States. On May 17, 2020 the American CDC reported that of 164,587 deaths from COVID-19 in the US, only $12(0.007 \%)$ were among children aged 0-14 years. Over the same period, among children aged 0-14 years, 111 died from pneumonia and 89 from influenza (CDC 2020).

Germany. One German study showed that the children who tested positive for COVID19 harbour just as much of the virus as adults (Drosten et al. 2020). This has led to speculation that children are as infectious as adults. However, several other recently published studies, particularly those that trace infections to identify index cases, show that this is not the case. Children are very rarely the source of infection in a household or a population. These tracing studies are consistent with each other: results from the United States, Australia, China, the Netherlands, Singapore, South Korea, and Vietnam all support the hypothesis that children are not the primary spreaders of the virus.

Italy. In the town of Vo in Italy, doctors screened $86 \%$ of the town's population and found that "no infections were detected in either survey in 234 tested children ranging from 0 to 10 years, despite some of them living in the same household as infected people" (Lavezzo et al. 2020, p. 5).

Japan. In a study that reviewed the 313 domestically acquired cases in Japan from January to March 2020, Mizumoto et al. (2020) concluded that "[c]hildren are less likely to be diagnosed as cases, and moreover, the risk of disease given exposure among children appears to be low".

The Netherlands. In April 2020, the Dutch National Institute for Public Health and the Environment reported that "children play a small role in the spread of the novel coronavirus. The virus is mainly spread between adults and from adult family members to children. Cases of children infecting each other or children infecting adults are less common".

To supplement these findings, a range of synthesis studies review evidence across several countries and studies, to draw our their similarities and differences. A review of 67 studies on COVID-19 and children concluded that "[t]he role of children in transmission is unclear, but it seems likely they do not play a significant role" (DFTB 2020, p. 8). In a review of 31 household transmission clusters from China, Singapore, the US, South Korea, and Iran, only three households (10\%) had a child as the index case (Zhu et al. 2020). To put this in perspective, during the H5N1 outbreak, children were the index case in $54 \%$ of cases (Zhu et al. 2020). Zhu et al. concluded that "Whilst SARS-CoV-2 can cause mild disease in children, the data available to date suggests that children have not played a substantive role in the intra-household transmission of SARS-CoV-2" (p. 2).

In their April 2020 paper, paediatric infectious disease experts Munro and Faust (2020) summarised three recent studies: "A case study of a cluster in the French Alps included a child with COVID-19 who failed to transmit it to any other person, despite exposure to more than a hundred children in different schools and a ski resort (Danis et al. 2020). In New South Wales, Australia, none of 735 students and 128 staff contracted COVID-19 from nine child and nine adult initial school cases, despite close contact (NSW 2020). In the Netherlands, separate data from primary care and household studies suggests SARS$\mathrm{CoV}-2$ is mainly spread between adults and from adult family members to children (RIVM 2020)".

Highly consistent research is emerging across all countries. In brief, children are less likely to get infected (either from each other or from adults) and they are less likely to 
transmit COVID-19, even when they get infected. The literature on COVID-19 is being rapidly updated as new papers come out. Don't Forget the Bubbles (2020) is a helpful website that summarizes new paediatric COVID-19 literature as it comes out. It is managed by paediatric infectious disease experts Alison Boast, Alasdair Munro, and Henry Goldstein.

\section{Are children less susceptible than adults?}

Munro (2020) summarized five studies looking specifically at whether children catch the disease at the same rate as adults after they are exposed to a confirmed positive case (an index case). The first study came from Shenzen in China, where researchers looked at 1286 contacts exposed to 391 positive cases. They found that children caught the disease at the same rate as adults $(7.4 \%$ for children $<10$ years vs. a population average of $6.6 \%$ ) ( $\mathrm{Bi}$ et al. 2020). This finding caused a lot of concern, but four more recent studies all show that children are significantly less likely to get infected compared to adults.

The next study came from Japan, evaluating 2496 contacts exposed to 313 positive cases. The authors found that children were much less likely to get the disease after exposure. Among children aged 0-19 years who were exposed, 7.2\% of boys were infected and $3.8 \%$ of girls were infected, compared to $22 \%$ of males and females aged 50-59 (Mizumoto et al. 2020).

The third study came from Guangzhou in China. After a study of close contacts of 212 positive cases, the authors found that children were much less likely to get infected $(5.3 \%)$ compared to adults (12.6\%) after exposure (Jing et al. 2020).

The fourth study came from Wuhan in China and looked at 392 contacts exposed to 105 positive cases. They found that only $4 \%$ of children $(<18)$ became infected compared to $17 \%$ of adults (Li et al. 2020).

The last study came from Hunan in China, where researchers traced 7375 contacts exposed to 136 positive cases. They found that adults aged 15-64 were about four times as likely to get infected compared to those 14 and under (Zhang et al. 2020).

To quote Munro's (2020) summary of these five studies, “we have five studies assessing the secondary attack rate of COVID-19 across age groups, in which four report a considerably lower attack rate in children and one which reports the same in children as the general population. It appears fairly convincing that children are less likely to acquire the infection than adults, by a significant amount”.

\section{Infection rates by age in South Africa}

While South Africa has a considerably smaller number of infections and fatalities compared to any of the countries reviewed above, the age profile of infections and deaths is consistent with the international experience. As of May 2, 2020, 123 people had died of COVID-19 in South Africa but none of the victims were under 20 years of age (NICD 2020). Of the 3144 positive cases of COVID-19 in South Africa (as of April 19, 2020), only $0.3 \%$ were aged $0-10$ and $4 \%$ were aged $11-20$. The two figures below present the full set of data. 


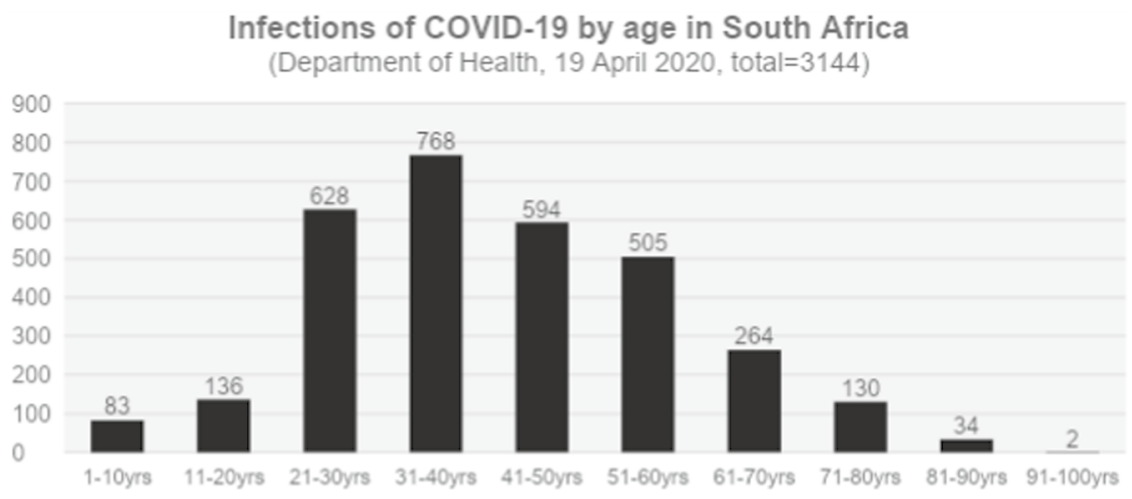

\section{Deaths from COVID-19 by age in South Africa \\ (Source: NICD, 2 May 2020, total=123)}

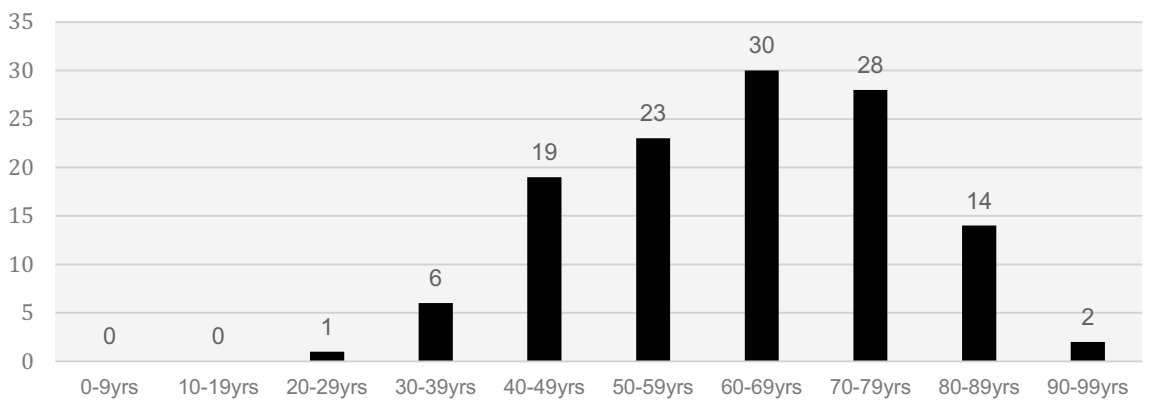

\section{Do school closures help?}

In a widely cited study published in the Lancet Journal of Child and Adolescent Health, Viner et al. (2020) conducted a rapid systematic review on the effectiveness of school closures in limiting the spread of COVID-19. They concluded as follows: "Data from the SARS outbreak in mainland China, Hong Kong, and Singapore suggest that school closures did not contribute to the control of the epidemic...Recent modelling studies of COVID-19 predict that school closures alone would prevent only $2-4 \%$ of deaths, much less than other social distancing interventions" (2020, p. 397). In another article, published in Science and also modelling the impacts of different interventions to limit the spread of COVID-19, Zhang et al. (2020) used contact surveys of 136 confirmed index cases infected in Wuhan and Shanghai. They determined that "social distancing alone, as implemented in China during the outbreak, is sufficient to control COVID-19" (2020, p. 4). But they also argued that school closures can help to flatten the curve: "While proactive school closures cannot interrupt transmission on their own, they can reduce peak incidence by 40-60\% and delay the epidemic" (2020, p. 1). It should be noted that, while Zhang et al. (2020) did consider age-specific susceptibility to infection (p. 2), they did not consider age-specific 
transmissibility or infectiousness (i.e., whether transmission rates are different for different ages). See "Modelling SARS-CoV-2 transmission" in the supplementary materials (p. 31 ) to Zhang et al. (2020), where a common transmission parameter applies to all ages. If it is true that children are less likely to transmit the virus when infected, which seems likely, given the above findings from the literature (e.g., RIVM 2020), then the assumptions underlying the school closure analysis are incorrect and overestimate the gains from school closures.

\section{Are children continuing to learn at home during lockdown in South Africa?}

It is difficult to answer this question definitively, but, given what we know about learning losses during holiday periods, the lack of access to technology and educational materials at home for the poorest $70 \%$ of South African children, and the lack of preparation for distance learning before the lockdown started, the short answer to this question is no. Realistically, for the poorest $80 \%$ of learners in South Africa, virtually no curricular learning is taking place during lockdown.

Apart from the fact that parents and caregivers are not trained or equipped to teach their own children, the existing lockdown "plans" for learning will not significantly mitigate the losses in learning for children that do not have proper technology-enabled learning at home. At most, 5-10\% of learners can continue learning at home given their access to computers and the internet. Data from the Trends in International Mathematics and Science Study (TIMSS 2015, Grade 9) shows that for no-fee schools (the poorest 75\%), less than half of children in a given class have a computer with the internet. Only in the wealthiest $5 \%$ of schools do at least $90 \%$ of learners have access to a computer and the internet at home (Gustafsson 2020).

The DBE's partnership with the South African Broadcasting Corporation (SABC) to provide "COVID-19 Learner Support" via television and radio (DBE 2020), while admirable, is not a replacement for school. It targets only "Grade 10-12 and ECD" and is only available for $1.5 \mathrm{~h}$ per day across three television channels. Given that these programs would need to be subject- and grade-specific for students to continue with curricular work, this still amounts to less than 5\% of the 'instruction' time learners would be receiving if they were in school, assuming they watch all the programs dedicated to their grade. It is also not clear what children in Grades R-9 are meant to do.

Access to computers and the internet in South African homes is very low. The General Household Survey of 2018 shows that only $22 \%$ of households have a computer in them (StatsSA 2020, p. 63) and only $10 \%$ of respondents have an internet connection in their home (p. 57). While it is true that $90 \%+$ of South African households report access to a mobile phone (p. 56), only $60 \%$ report access to the internet via their mobile phone. It should further be emphasised that these rates are for adults in the household. One cannot assume that during lockdown, children in a household would have exclusive or unlimited access to the cell phone to access educational content. There is also the issue of multiple children in the same household needing to share a mobile phone, and the high cost of data, although there are now some free educational sites (Duncan-Williams 2020). 
Given the practical impossibility of continuing with meaningful learning from home, at least for the poorest $80 \%$ of learners, the Department of Basic Education should emphasize making schools safe for learners and teachers to return.

\section{What are the costs of lockdowns and school closures?}

Globally, the focus of the world's attention is almost exclusively on infections and deaths specifically from COVID-19. However, the various measures taken to limit the spread of the virus, such as lockdowns and school closures are not costless. For example, Crawley et al. (2020, p. 1) report that "In the UK, paediatricians are increasingly concerned that parental worries over visiting healthcare centres are leading to a drop in vaccination rates and the late presentation of serious illness in children. This is likely to cause avoidable deaths and illness in the short and long term, a form of collateral damage from the COVID-19 emergency". Similar experiences have been reported in Italy: "During Italy's national lockdown for coronavirus disease 2019 (COVID-19), official hospital statistics in the period March 1-27, 2020, show substantial decreases-ranging from 73 to $88 \%$ - in paediatric emergency department visits compared with the same time period in 2019 and 2018. Similarly, family paediatricians widely report a considerable reduction in clinic visits" (Lazzerini et al. 2020, p. 10). Given the higher rates of child and maternal mortality in developing countries, as well as the higher rates of co-morbidities such as tuberculosis and HIV, these are worrying portents. A recent study by Robertson et al. (2020) argues that over a 6-month period child deaths would increase by between 253,500 and 1,157,000 depending on the underlying assumptions. They conclude that "If routine health care is disrupted and access to food is decreased (as a result of unavoidable shocks, health system collapse, or intentional choices made in responding to the pandemic), the increase in child and maternal deaths will be devastating" (Robertson et al. 2020, p. 1).

In the context which I know best, South Africa, there are a number of reasons why the collateral damage from the lockdowns may be severe. In a recent Conversation article, five South African economists predict that "the lockdown could lead to a 50\% increase in the national rate of extreme poverty... This means that an additional four million South Africans will be unable to afford enough food" (Bassier et al. 2020).

\section{Conclusion}

South Africa's choice to re-open schools is in keeping with a number of other countries that have had far greater COVID-19 outbreaks and sometimes shorter lockdown periods. These countries include China, Denmark, Israel, Finland, France, Germany, Japan, and the Netherlands. In all these cases, governments are introducing precautionary measures such as temperature checks, reduced class sizes, holding classes outside, and spacing desks further apart.

Deciding to re-open schools and bring children back in a phased-in approach will involve many administrative complexities. These include how to manage the infection risks for adults that facilitate schooling, including teachers, principals, administrative staff, transport workers, and dining service employees. Temporarily replacing high-risk individuals, such as those older than 60 or those with diabetes and other pre-existing conditions, 
will not be simple or easy. Yet this should be held in tension with the severe limitations imposed by school closures - to children's ability to learn, to caregivers' ability to earn an income, and to the economy's ability to function. The economy cannot properly 're-open' while schools are closed. This is especially true for schooling among those 10 years of age and younger, who require the most care at home. Furthermore, the costs of keeping children "locked up" at home, and the economy "locked down" are severe. Any decision to re-open schools and the economy needs to balance the costs and benefits not only to COVID infections and deaths, but also the unintended indirect suffering and deaths from these mitigation strategies.

The aim of this Viewpoint has been to summarize some of the emerging international evidence. The latest evidence suggests that by allowing the youngest children to go back first, policymakers would put teachers and parents at lower risk than if high-school learners went back to school first. As two paediatric infectious disease experts explained, "[s]evere COVID-19 is as rare as many other serious infection syndromes in children that do not cause schools to be closed" (Munro and Faust 2020, p. 2).

As the Department of Basic Education in South Africa considers when and how to bring children and teachers back to school, it would be wise to heed the epidemiological evidence emerging from around the world. Younger children are far less likely to catch or transmit the COVID-19 virus, so bringing them back to school first is the safest approach: for them, for their teachers, and for the health of our economy and society as a whole.

\section{References}

Bassier, I., Budlender, J., Leibbrandt, M., Zizzamia, R., \& Ranchhod, V. South Africa can—and shouldtop up child support grants to avoid a humanitarian crisis. The Conversation. https://theconversation .com/south-africa-can-and-should-top-up-child-support-grants-to-avoid-a-humanitarian-crisis-135222.

BBC News (2020). Coronavirus: Switzerland says young children can hug grandparents. https://www.bbc. com/news/world-europe-52470838.

Bi, Q., Wu, Y., Mei, S., Ye, C., Zou, X., Zhang, Z., et al. (2020). Epidemiology and transmission of COVID19 in 391 cases and 1286 of their close contacts in Shenzhen: A retrospective cohort study. Lancet Infectious Diseases, 27 April. https://doi.org/10.1016/S1473-3099(20)30287-5.

CDS [Centers for Disease Control and Prevention] (2020). Provisional death counts for coronavirus disease by sex, age, and state (COVID-19). https://www.cdc.gov/nchs/nvss/vsrr/covid_weekly/index.htm.

Crawley, E., Loades, M., Feder, G., et al. (2020). Wider collateral damage to children in the UK because of the social distancing measures designed to reduce the impact of COVID-19 in adults. BMJ Paediatrics Open.. https://doi.org/10.1136/bmjpo-2020-000701.

Danis, K., Epaulard, O., Bénet, T., et al. (2020). Cluster of coronavirus disease 2019 (COVID-19) in the French Alps, 2020. Clinical Infectious Diseases. https://doi.org/10.1093/cid/ciaa424.

Department of Basic Education, South Africa (2020). Basic Education and SABC launch Coronavirus COVID-19 TV and radio curriculum support programmes for learners. https:/www.gov.za/speeches/ basic-education-and-sabc\% C2\%A0launch\%C2\%A0coronavirus-covid-19-tv-and-radio-curriculum -support.

Don't Forget the Bubbles (2020). An evidence summary of paediatric COVID-19 literature. https://dontf orgetthebubbles.com/evidence-summary-paediatric-covid-19-literature/.

Drosten, C et al. (2020). An analysis of SARS-CoV-2 viral load by patient age. Charite Research Network Zoonotic Infectious Diseases. https://zoonosen.charite.de/fileadmin/user_upload/microsites/m_cc05/ virologie-ccm/dateien_upload/Weitere_Dateien/analysis-of-SARS-CoV-2-viral-load-by-patient-age. pdf.

Duncan-Williams, K. (2020). South Africa's digital divide detrimental to the youth. Mail \& Guardian. https ://mg.co.za/article/2020-04-19-south-africas-digital-divide-detrimental-to-the-youth/.

Gudbjartsson, D. F., Helgason, A., Jonsson, H., Magnusson, O. T., Melsted, P., Norddahl, G. L., et al. (2020). Spread of SARS-CoV-2 in the Icelandic population. New England Journal of Medicine. https:// doi.org/10.1056/NEJMoa2006100. 
Gustafsson, M. (2020). Basic education: The coronavirus. Pretoria: Department of Basic Education.

Jeong et al. (2020). Short communication: Submitted to Osong public health and research perspectives coronavirus disease-19: The first 7,755 cases in the republic of Korea. https://www.medrxiv.org/conte nt/10.1101/2020.03.15.20036368v1.full.pdf.

Jing, Q. L., Liu, M. J., Yuan, J., Zhang, Z. B., Zhang, A. R., Dean, N. E., et al. (2020). Household secondary attack rate of COVID-19 and associated determinants. medRxiv, 1-22. https://doi. org/10.1101/2020.04.11.20056010.

Lavezzo, E., Franchin, E., Ciavarella, C., Cuomo-Dannenburg, G., Barzon, L., Del Vecchio, C., et al. (2020). Suppression of COVID-19 outbreak in the municipality of Vo, Italy. medRxiv. https://doi. org/10.1101/2020.04.

Lazzerini, M., Barbi, E., Apicella, A., Marchetti, F., Cardinale, F., \& Trobio, G. (2020). Delayed access of provision of care in Italy resulting from fear of COVID-19. Lancet Child Adolesc Health, 2020(4), e10-e11.

Li, W., Zhang, B., Lu, J., Liu, S., Chang, Z., Cao, P., et al. (2020). The characteristics of household transmission of COVID-19. Clinical Infectious Diseases. https://doi.org/10.1093/cid/ciaa450.

Mizumoto, K., Omori, R., \& Nishiura, H. (2020). Age specificity of cases and attack rate of novel coronavirus disease (COVID-19). medRxiv, 1-6. https://doi.org/10.1101/2020.03.09.20033142.

Munro, A. (2020). The missing link? Children and transmission of SARS-CoV-2. Don't Forget the Bubbles. https://doi.org/10.31440/DFTB.25585.

Munro, A. P. S., \& Faust, S. N. (2020). Children are not COVID-19 super spreaders: Time to go back to school. Archives of Disease in Childhood. https://doi.org/10.1136/archdischild-2020-319474.

NCIRS [National Centre for Immunisation Research and Surveillance], New South Wales, Australia (2020). Covid-19 in schools: The experience in NSW. Sydney: Government of New South Wales. http://ncirs .org.au/sites/default/files/2020-04/NCIRS\%20NSW\%20Schools\%20COVID_Summary_FINAL \%20public_26\%20Apri1\%202020.pdf.

National Institute for Communicable Diseases, South Africa (2020). COVID-19 update. https://www.nicd. ac.za/covid-19-update-46/.

Our World in Data (2020). Case fatality rate for COVID-19 by age. https://ourworldindata.org/coronaviru s\#case-fatality-rate-of-covid-19-by-age.

RIVM (2020). Children and COVID-19. Dutch National Institute for Public Health and the Environment. https://www.rivm.nl/en/novel-coronavirus-covid-19/children-and-covid-19.

Robertson, R., Carter, E., Chou, V., et al. (2020). Early estimates of the indirect effects of the COVID-19 pandemic on maternal and child mortality in low-income and middle-income countries: A modelling study. Lancet Global Health. https://doi.org/10.1016/S2214-109X(20)30229-1.

RTS News (2020). Daniel Koch: "Je suis sûr de notre analyse concernant les enfants". https://www.rts.ch/ info/suisse/11291943-daniel-koch-je-suis-sur-de-notre-analyse-concernant-les-enfants-.html.

Science Museum Group (2020). Coronavirus: Hunting down COVID-19. https://www.sciencemuseumgr oup.org.uk/blog/hunting-down-covid-19/.

StatsSA (2020). General household survey 2018. http://www.statssa.gov.za/publications/P0318/P03182018. pdf.

Viner, R. M., Russell, S. J., Croker, H., et al. (2020). School closure and management practices during coronavirus outbreaks including COVID-19: A rapid systematic review. Lancet Child \& Adolescent Health. https://doi.org/10.1016/S2352-4642(20)30095-X.

Zhang, J., Litvinova, M., Liang, Y., Wang, Y., et al. (2020). Changes in contact patterns shape the dynamics of the COVID-19 outbreak in China. Science. https://doi.org/10.1126/science.abb8001.

Zhu, Y., Bloxham, C. J., Hulme, K. D., Sinclair, J. E., et al. (2020). Children are unlikely to have been the primary source of household SARS-CoV-2 infections. medRxiv 1-31. https://doi.org/10.1101/2020.03.26.20044826.

Publisher's Note Springer Nature remains neutral with regard to jurisdictional claims in published maps and institutional affiliations.

Nic Spaull (South Africa) is a senior researcher at the Research on Socioeconomic Policy (RESEP) group in the Economics Department, Stellenbosch University. His research interests center on education policy in South Africa and sub-Saharan Africa, as well as early grade reading and assessment in African languages. He consults for UNESCO, the OECD, the World Bank, the South African Presidency, and advises a number of Trusts and Foundations. He is also the director of the Funda Wande: Reading for Meaning project, an open-access multi-media course to teach Foundation Phase teachers (grades R-3) how to teach reading and writing. 